\title{
DETERMINAÇÃO DO POTENCIAL ANTIOXIDANTE IN VITRO DE FRUTOS DO CERRADO BRASILEIRO ${ }^{1}$
}

\author{
MÔNICA LOPES MORAIS ${ }^{2}$, ANNE CAROLINE RODRIGUES SILVA², \\ CLINÁSCIA RODRIGUES ROCHA ARAÚJO³, ELIZABETHE ADRIANA ESTEVES ${ }^{2}$, \\ NÍSIA ANDRADE VILLELA DESSIMONI-PINTO²
}

RESUMO-Extratos em metanol e acetona de diferentes espécies do Cerrado, semente de Solanum lycocarpum A. St.-Hil (Lobeira), polpa de Byrsonima verbascifolia (L.) DC. (Murici), epicarpo e mesocarpo de Caryocar brasiliense Cambess (Pequi) e pendúculo de Cipocereus minensis F. Ritter (Quiabo-da-lapa) foram submetidos a ensaios antioxidantes in vitro para avaliar a capacidade de sequestrar os radicais orgânicos DPPH e ABTS.+, reduzir o ferro (FRAP) e/ ou inibir a peroxidação lipídica ( $\beta$-caroteno). Todas as amostras apresentaram considerável atividade antioxidante, embora em diferentes proporções, destacando-se o mesocarpo de Caryocar brasiliense como o responsável pela maior atividade antioxidante por captura de radicais livres (DPPH e ABTS) e poder de redução do metal (FRAP) e o pendúnculo de Cipocereus minensis frente à inibição da peroxidação lipídica (B-caroteno). Os frutos estudados podem ser considerados fontes potenciais de antioxidantes naturais e podem ser explorados como aditivos alimentares promissores para a prevenção de doenças, bem como para a manutenção da saúde.

Termos para Indexação: Solanum lycocarpum A.St.-Hil; Byrsonima verbascifolia (L.) DC.; Caryocar brasiliense Cambess; Cipocereus minensis F.Ritter, radicais orgânicos, saúde.

\section{DETERMINATION OF ANTIOXIDANT POTENTIAL IN VITRO OF BRAZILIAN CERRADO FRUITS}

\begin{abstract}
Methanol and acetone extracts from different species of Brazilian Cerrado, seeds of Solanum lycocarpum A.St. -Hil (Lobeira), pulp of Byrsonima verbascifolia (L.) DC. (Murici), epicarp and mesocarp of Caryocar brasiliense Cambess (Pequi) and penducle of Cipocereus minensis F.Ritter (Quiabo-da-lapa) were submitted to in vitro antioxidant tests to evaluate the capacity to sequester organic radicals DPPH and $\mathrm{ABTS}^{+}$, , to reduce the iron (FRAP) and to inhibit the lipid peroxidation ( $\beta$-carotene). All samples showed considerable antioxidant activity, but in different proportions, highlighting the mesocarp of Caryocar brasiliense as responsible for the higher antioxidant activity by capturing free radicals (DPPH and ABTS) and power reduction of the metal (FRAP) and peduncle of Cipocereus minensis in the inhibition of lipid peroxidation (B-carotene). The studied fruits could be considered potential sources of natural antioxidants and could be exploited as promising feed additives for the prevention of diseases and health maintenance. Index terms: Solanum lycocarpum A.St.-Hil; Byrsonima verbascifolia (L.) DC.; Caryocar brasiliense Cambess; Cipocereus minensis F.Ritter, organic radicals, health.
\end{abstract}

\footnotetext{
1(Trabalho 235-12). Recebido em: 28-08-2012. Aceito para publicação em : 19-04-2013.

${ }^{2}$ Laboratório de Tecnologia e Biomassas do Cerrado, Universidade Federal dos Vales do Jequitinhonha e Mucuri - UFVJM. Rodovia MGT 367 - Km 583, nº 5000, Alto da Jacuba. 39100-000. Diamantina - MG. Brazil. E-mails: monicalopes_m@hotmail.com; carol rodrisilva@hotmail.com; eaesteves@yahoo.com.br; nisiavillela@yahoo.com.br

${ }^{3}$ Departamento de Química, ICEx, Universidade Federal de Minas Gerais - UFMG. Av. Presidente Antônio Carlos, 6627 Pampulha, 31.270-901. Belo Horizonte-MG. Brazil. E-mail: clinascia2r@yahoo.com.br
} 


\section{INTRODUÇÃO}

Diversas doenças crônicas não transmissíveis e degenerativas (NEVES, 2012), como o câncer, doenças cardíacas, Alzheimer, aterosclerose e até o envelhecimento precoce, têm sido associadas a um desequilíbrio entre a produção de radicais livres e antioxidantes. Os radicais livres são capazes de causar modificações estruturais por serem altamente reativos com moléculas de DNA, proteínas, carboidratos e/ ou lipídios, levando-os a estados patológicos ou a apoptose (ARTS; HOLLMAN, 2005).

Diante disso, a presença de compostos bioativos, como os antioxidantes (NEVES, 2012), tem-se mostrado uma boa alternativa de proteção para o corpo humano contra radicais livres, atuando na prevenção e no tratamento de enfermidades (VALKO et al., 2007).

Antioxidantes podem ser definidos como quaisquer substâncias que, presentes em baixas concentrações, quando comparados a um substrato oxidável, atrasam ou inibem a oxidação desse substrato de maneira eficaz. Antioxidantes são classificados de acordo com o mecanismo de ação em primários (doadores de átomos de hidrogênio), biológicos (enzimas) e/ou quelantes de metais (MOURE et al., 2001).

Diferentes técnicas têm sido desenvolvidas a fim de determinar a atividade antioxidante in vitro. No entanto, esta diversidade de metodologias gera resultados numéricos difíceis de serem comparados, uma vez que não há um método universal capaz de medir a capacidade antioxidante de todas as amostras com precisão, já que os mecanismos antioxidantes se demonstram diferentes (PRIOR et al., 2005).

A presença de antioxidantes em frutas e hortaliças tem aumentado o consumo destes produtos no mercado nacional e internacional. $\mathrm{O}$ Brasil, portanto, possui número significativo de espécies frutíferas, nativas e exóticas, ainda não exploradas. Tais espécies são alvos potenciais para a agroindústria, que valoriza o caráter exótico dos frutos, além da presença de compostos capazes de prevenir doenças e impulsionar mercados econômicos (ALVES et al., 2008). Todavia, durante o processamento de frutas, diferentes resíduos, como cascas, sementes, caroços ou bagaço, não são aproveitados, embora contenham maiores níveis de compostos antioxidantes, quando comparados com sua porção comestível (LEONG; SHUI, 2002; CONTRERAS-CALDERÓN et al., 2011).

Considerando a ausência de estudos sobre o potencial antioxidante de resíduos de frutos de espécies nativas do Cerrado, o presente trabalho teve como objetivo quantificar, por diferentes metodologias, a atividade antioxidante de semente de Solanum lycocarpum, epicarpo e mesocarpo de Caryocar brasiliense, pendúculo de Cipocereus minensis e polpa de Byrsonima verbascifolia, popularmente conhecidos como lobeira ou fruta-do-lobo, pequi, quiabo-da-lapa e murici, respectivamente.

\section{MATERIAL E MÉTODOS}

Frutos maduros de Solanum lycocarpum, Byrsonima verbascifolia, Caryocar brasiliense e Cipocereus minensis foram coletados $(\mathrm{n} \geq 10)$ em locais distintos, no Alto Vale Jequitinhonha, cidade de Diamantina (Estado de Minas Gerais, Brasil), em janeiro de 2010. Foram coletados frutos maduros que já haviam caído das respectivas frutíferas. A identidade do material vegetal foi avaliada baseandose em características morfológicas, bem como em comparações com espécies disponíveis no herbário da Universidade Federal dos Vales do Jequitinhonha e Mucuri - UFVJM.

Após a coleta, os pendúculos de Cipocereus minensis foram rapidamente expostos ao fogo (10 segundos) para a eliminação dos espinhos. As sementes de Solanum lycocarpum, a polpa de Byrsonima verbascifolia e o mesocarpo interno e o epicarpo de Caryocar brasiliense foram separados manualmente. Posteriormente, as porções dos frutos em estudo foram submetidas à secagem em estufa com circulação forçada de ar (Nova Ética, 400 1ND, São Paulo) a $40 \pm 5^{\circ} \mathrm{C}$, por aproximadamente 7 dias; em seguida, foram trituradas e peneiradas para obtenção de farinhas homogêneas (padronizadas a 80 mesh).

A extração de antioxidantes foi realizada pelo método descrito por Larrauri et al. (1997). Amostras $(1,0 \mathrm{~g})$ de farinha de pendúculo de Cipocereus minensis, sementes de Solanum lycocarpum, polpa de Byrsonima verbascifolia, mesocarpo interno de Caryocar brasiliense e epicarpo de Caryocar brasiliense foram extraídos com $40 \mathrm{~mL}$ de solução metanol a $50 \%$ (metanol/água; $1: 1)$ por $1 \mathrm{~h}$, à temperatura ambiente. A mistura foi centrifugada a $3.000 \mathrm{rpm}$ em centrífuga (Biosystems, Modelo 80-2B, Curitiba-PR) por 15 min. O sobrenadante foi coletado, e o processo repetido, usando $40 \mathrm{~mL}$ de solução de acetona a 70\% (acetona/água; 7:3). Após a evaporação do solvente, as misturas foram diluídas em metanol em diferentes concentrações, permitindo a obtenção dos seguintes tratamentos: A $(0,50 \mathrm{mg} / \mathrm{mL}, 0,05 \mathrm{p} / \mathrm{v}) ; B(1,00 \mathrm{mg} / \mathrm{mL}, 0,1 \mathrm{p} / \mathrm{v})$, e $\mathrm{C}(1,50 \mathrm{mg} / \mathrm{mL}, 0,15 \mathrm{p} / \mathrm{v})$.

A atividade de captura do radical livre 
DPPH foi medida pelo método de Brand-Williams, Cuvelier e Berset (1995). Em ambiente escuro, uma alíquota $(0,10 \mathrm{~mL})$ das amostras $\mathrm{A}-\mathrm{C}$ de pendúculo de Cipocereus minensis, sementes de Solanum lycocarpum, polpa de Byrsonima verbascifolia, mesocarpo interno de Caryocar brasiliense e epicarpo de Caryocar brasiliense foram adicionados de $3,9 \mathrm{~mL}$ de solução DPPH $0,06 \mathrm{mM}$. A mistura foi vigorosamente agitada e incubada por 30 minutos, a $37^{\circ} \mathrm{C}$. A absorbância das amostras foi determinada em espectrofotômetro (Shimadzu, Modelo Mini 1.240 UV-VIS, Japão) e foram registradas em $\lambda=$ $515 \mathrm{~nm}$. Os resultados foram apresentados como $\mathrm{EC}_{50}$, que corresponde à concentração de $50 \%$ de radicais em relação à concentração inicial da amostra (SÁNCHEZ-MORENO et al., 1998).

A atividade de captura de radical livre $\mathrm{ABTS}^{++}$ foi medida pelo método de Arnao, Cano e Acosta (2001). O cátion $\mathrm{ABTS}^{\cdot+}$ foi gerado por $5,0 \mathrm{~mL}$ de solução-estoque de $\mathrm{ABTS}^{++}$com $88,0 \mu \mathrm{L}$ de solução de persulfato de potássio. A mistura foi deixada em repouso, no escuro, durante $16 \mathrm{~h}$, à temperatura ambiente. A solução de $\mathrm{ABTS}^{\cdot+}(1,00 \mathrm{~mL})$ foi diluída em etanol até obter-se uma absorvância de $0,70 \mathrm{em}$ $734 \mathrm{~nm}$. No escuro, as amostras A-C $(0,03 \mathrm{ml})$ foram transferidas para tubos de ensaio com $3,00 \mathrm{~mL}$ da solução de radical $\mathrm{ABTS}^{\cdot+}$ e homogeneizadas. Após 6 min, as absorvâncias foram registradas.

A atividade antioxidante avaliada quanto ao poder de redução do Ferro foi medida pelo método de Firuzi et al. (2005). A solução FRAP foi preparada por adição de $25,0 \mathrm{~mL}$ de tampão acetato $300,0 \mathrm{mM}$ a $2,50 \mathrm{~mL}$ de cloreto férrico hexa-hidratado 20,0 $\mathrm{mM}$ e 2,50 $\mathrm{mL}$ de TPTZ 10,0 mM. Em um tubo de ensaio, as amostras A-C $(0,09 \mathrm{~mL})$ foram adicionadas a $0,27 \mathrm{~mL}$ de água destilada e $2,70 \mathrm{ml}$ de reagente FRAP. Após 30 min de incubação a $37^{\circ} \mathrm{C}$, os dados de absorvância foram registados em $\lambda=595 \mathrm{~nm}$. O potencial antioxidante dos extratos dos frutos, cascas, semente e pendúculo foi determinado com base numa curva de calibração, traçada usando $\mathrm{FeSO}_{4} .7 \mathrm{H}_{2} \mathrm{O}$ em concentrações que variaram entre 500 e $2.000 \mathrm{mM}$.

A atividade de inibição da oxidação de $\beta$-caroteno por radicais de peróxido foi baseada no método de Velioglu et al. (1998). Quantidades de 0,15 $\mathrm{mL}$ de uma solução de $\beta$-caroteno em clorofórmio (20 $\mathrm{mg} / \mathrm{mL}$ ) foi pipetada para um balão de fundo redondo contendo ácido linoleico $(0,12 \mathrm{~mL})$, Tween 40 (1,63 $\mathrm{mL})$ e as amostras A-C $(0,4 \mathrm{~mL})$. Posteriormente, procedeu-se à evaporação do clorofórmio a $40^{\circ} \mathrm{C}$. Os dados de absorbância foram registrados em $\lambda=$ $470 \mathrm{~nm}$, e o Trolox foi usado para fins de comparação.

Medidas de absorbância para a determinação da atividade antioxidante pelos métodos DPPH,
$\mathrm{ABTS}^{{ }^{+}}$, FRAP e $\beta$-caroteno foram realizadas em espectrofotômetro (Shimadzu, Modelo Mini 1.240 UV-VIS, Japão).

\section{RESULTADOS E DISCUSSÃO}

Frutas e legumes são as principais fontes de compostos antioxidantes (vitamina $\mathrm{E}$, vitamina $\mathrm{C}$, $\beta$-caroteno entre outros), que agem como varredores de radicais, tornando tais alimentos essenciais para a saúde humana (HOSSAIN; RAHMAN 2011).

As atividades antioxidantes das diferentes amostras avaliadas quanto à captura de radicais livres DPPH e $\mathrm{ABTS}^{\bullet+}$, bem como quanto ao poder de redução do $\mathrm{Fe}^{+3}$, estão apresentadas na Tabela 1 .

Para as amostras analisadas, a atividade antioxidante para a captura de radicais livres DPPH, em ordem decrescente, foi: mesocarpo de Caryocar brasiliense $>$ pendúnculo de Cipocereus minensis $>$ semente de Solanum lipocarpum $>$ epicarpo de Caryocar brasiliense $>$ polpa de Byrsonima verbascifolia.

Quanto à captura do radical $\mathrm{ABTS}^{\bullet+}$, a atividade antioxidante do mesocarpo de Caryocar brasiliense demostrou-se superior à apresentada pela semente de Solanum lipocarpum, pelo epicarpo de Caryocar brasiliense, pelo pendúnculo de Cipocereus minensis e pela polpa de Byrsonima verbascifolia.

No que diz respeito ao poder de redução do $\mathrm{Fe}^{+3}$, os melhores resultados foram apresentados por mesocarpo de Caryocar brasiliense, sendo seguido, em ordem decrescente, pela semente de Solanum lipocarpum $>$ pendúnculo de Cipocereus minensis $>$ polpa de Byrsonima verbascifolia e epicarpo de Caryocar brasiliense.

O sistema $\beta$ Caroteno/Ácido Linoleico avalia a capacidade de um antioxidante inibir a peroxidação do ácido linoleico a radicais livres, responsáveis pela descoloração do $\beta$-caroteno. Os resultados para a porcentagem de inibição da peroxidação lipídica para as amostras avaliadas estão na Tabela 2. O epicarpo de Caryocar brasiliense e o pendúculo de Cipocereus minensis apresentaram-se como as amostras com menor e maior atividade antioxidante, respectivamente.

O mesocarpo do pequi destacou-se em relação ao potencial antioxidante pela captura de radical livre $\mathrm{ABTS}^{+}$, , FRAP e $\beta$ Caroteno, enquanto o epicarpo de pequi apresentou resultados expressivos, quando comparado com os demais frutos avaliados, apenas para a captura do radical livre DPPH, embora sua atividade de captura do radical $\mathrm{ABTS}^{+}$e inibição da peroxidação lipídica seja significativa. A grande 
atividade antioxidante de captura de radicais livres verificada para o epicarpo e o mesocarpo do pequi pode estar relacionada com o fato de que este fruto é encontrado em regiões onde há grande incidência de luz responsável por favorecer o surgimento de cascatas de radicais livres e, consequentemente, de mecanismos capazes de combatê-los (LIMA et al., 2007).

De acordo com Roesler et al. (2007), extrato etanólico de semente mais polpa de lobeira foram testados quanto à atividade antioxidante de redução de radicais livres DPPH e apresentaram resultados $\left(\mathrm{EC}_{50=} 16.2970 \mathrm{mg} / \mathrm{L}\right)$ superiores aos aqui encontrados para o extrato metanólico das sementes desse fruto. Esta diferença sugere maior atividade antioxidante na polpa do fruto e consequente diluição das substâncias responsáveis por tal atividade, quando em extrato contendo ambas as frações do fruto (polpa e semente). O extrato aquoso de sementes de Solanum torvum, espécie também pertencente à família Solanaceae, teve alta atividade antioxidante pelo método DPPH (SIVAPRIYA; LEELA 2007), o que justifica o estudo de espécies desse gênero e família como potenciais fontes naturais de antioxidantes.

Rufino et al. (2010) encontraram, para os extratos aquosos da polpa e casca de Byrsonima dealbata, valor igual a $412 \mu \mathrm{M}$ de trolox/g, superior ao encontrado para a polpa de Byrsonima verbasci- folia, neste estudo. Embora de espécies diferentes, é possível sugerir a maior capacidade antioxidante nas cascas dos frutos de espécies desse gênero, quando comparada com suas polpas.

Já o quiabo-da-lapa é uma espécie pouco estudada em relação à atividade antioxidante, bem como aos prováveis benefícios que pode proporcionar a saúde. Portanto, os dados para a comparação ainda são escassos. Porém, em estudos realizados em cactus e pera do gênero Opuntia, pertencentes à mesma família do quiabo-da-lapa, Cactaceae, foram encontrados valores de ácido ascórbico e polifenóis equivalentes a $18,5 \mathrm{mg} \mathrm{AA} / 100 \mathrm{~g}$ e $218,8 \mathrm{mg}$ GAE$/ 100 \mathrm{~g}$, respectivamente, indicando as espécies dessa família como potenciais fontes de compostos bioativos com atividade antioxidante (FERNANDEZ-LOPEZ et al., 2010).

A capacidade antioxidante total varia, consideravelmente, de um tipo de fruta para a outra (MOKBEL; HASHINAGA 2006). Contudo, nossos dados indicam a presença de diferentes compostos antioxidantes nas frações dos frutos avaliados, embora variável quanto ao modo de inibição da oxidação.

Deverão ser realizados mais estudos para determinar a composição química destes materiais, especialmente o conteúdo de compostos fenólicos totais, vitaminas e fitoquímicos, bem como sua toxicidade. Estas informações poderão ser usadas para melhor compreensão dos efeitos antioxidantes, bem como para certificar a segurança da ingestão destes como alimento.

TABELA 1 - Atividade Antioxidante Total (AAT) em frutos do Cerrado Brasileiro, segundo métodos de Captura do Radical Livre - DPPH, Captura do Radical Livre - ABTS e Redução do Ferro - FRAP Amostras Atividade Antioxidante Total (AAT)

\begin{tabular}{ccc}
$\mathrm{DPPH}$ & ABTS & FRAP \\
$\left(\mathrm{EC}_{50} \mathrm{mg} / \mathrm{L}\right)$ & $(\mathrm{uM}$ trolox/g) & $(\mathrm{uM}$ sulfato ferroso/g) \\
\hline
\end{tabular}

Semente Solanum lycocarpum

Polpa Byrsonima verbascifolia Epicarpo Caryocar brasiliense Mesocarpo Caryocar brasiliense Pendúnculo ciporeceus minensis

*Valor expresso como média $(\mathrm{n}=3) \pm$ desvio-padrão.

$\begin{array}{rrr}410,00 * \pm 0,015 & 820,00 \pm 0,083 & 167,11 \pm 0,219 \\ 1.800,00 \pm 0,005 & 15,63 \pm 0,001 & 148,42 \pm 0,047 \\ 765,00 \pm 0,013 & 543,18 \pm 0,108 & 14,99 \pm 0,004 \\ 188,50 \pm 0,115 & 1.230,00 \pm 0,125 & 2.085,70 \pm 0,533 \\ 250,00 \pm 0,009 & 271,00 \pm 0,024 & 151,67 \pm 0,043\end{array}$

$410,00 * \pm 0,015$

$820,00 \pm 0,083$

$167,11 \pm 0,219$

(48,42 $\pm 0,047$

$085,70 \pm 0,533$

$271,00 \pm 0,024$

$151,67 \pm 0,043$

TABELA 2 - Atividade Antioxidante Total (AAT) em frutos do Cerrado Brasileiro, segundo o método Sistema $\beta$-Caroteno/ Ácido Linoleico (\% Inibição), nas concentrações de $500 \mathrm{mg} / \mathrm{L}, 1.000 \mathrm{mg} / \mathrm{L}$ e $1.500 \mathrm{mg} / \mathrm{L}$.

\begin{tabular}{lccc}
\hline Amostras & Sistema $\beta$ Caroteno/ & Ácido Linoleico- & \% Inibição \\
\hline Concentrações (mg/L) & 500 & 1000 & 1500 \\
\hline Semente Solanum lycocarpum & $58,94 * \pm 0,045$ & $61,06 \pm 0,041$ & $66,35 \pm 0,035$ \\
Polpa Byrsonima verbascifolia & $52,40 \pm 0,050$ & $63,46 \pm 0,038$ & $67,79 \pm 0,033$ \\
Epicarpo Caryocar brasiliense & $29,81 \pm 0,073$ & $41,35 \pm 0,060$ & $42,31 \pm 0,061$ \\
Mesocarpo Caryocar brasiliense & $69,23 \pm 0,033$ & $81,25 \pm 0,020$ & $83,65 \pm 0,018$ \\
Pendúnculo Cipocereus minensis & $79,33 \pm 0,021$ & $83,65 \pm 0,017$ & $84,62 \pm 0,016$ \\
\hline
\end{tabular}

*Valor expresso como média $(\mathrm{n}=3) \pm$ desvio-padrão. 


\section{CONCLUSÃO}

1-A semente de Solanum lycocarpum (Lobeira), a polpa de Byrsonima verbascifolia (Murici), o epicarpo e o mesocarpo de Caryocar brasiliense (Pequi) e o pendúculo de Cipocereus minensis (Quiabo-da-lapa) mostram considerável potencial antioxidante.

2-O mesocarpo de Caryocar brasiliense apresenta maior potencial antioxidante, por captura de radicais livres (DPPH e ABTS) e poder de redução do metal (FRAP) e o pendúnculo de Cipocereus minensis frente à inibição da peroxidação lipídica (B-caroteno).

3-Assim, os frutos estudados podem ser considerados fontes potenciais de antioxidantes naturais e serem explorados a fim de promover a saúde.

\section{REFERÊNCIAS}

ALVES, R. E.; BRITO, E. A.; RUFINO, M. S. M.; SAMPAIO, C. G. Antioxidant activity measurement in tropical fruits: A case study with acerola. Acta Horticulturae, Belgium, v. 773, n. 1, p. 299-305, 2008.

ARNAO, M. B.; CANO, A.; ACOSTA, M. The hydrophilic and lipophilic contribution to total antioxidant activity. Food Chemistry, London, v. 73, n. 2, p. 239-244, 2001.

ARTS, I.C.W.; HOLLMAN, C.H. Polyphenols and disease risk in epidemiologic studies, American Journal of Clinical Nutrition, Bethesda, v. 81, n. 1, p. 317-325, 2005.

BRAND-WILIAMS, W.; CUVELIER, M.E.; BERSET, C. Use of a free radical method to evaluate antioxidant activity. Food Science and Technology, London, v. 28, n. 1, p. 25-30, 1995.

CONTRERAS-CALDERÓN, J.; CALDERÓNJAIMES，L.; GUERRA-HERNÁNDEZ，E.; GARCÍA-VILLANOVA, B. Antioxidant capacity, phenolic content and vitamin $\mathrm{C}$ in pulp, peel and seed from 24 exotic fruits from Colombia. Food Research International, Essex, v.44, n. 7, p. 2047-2053, 2011.

FERNANDEZ-LOPEZ, J.A.; ALMELA, L.; OBON, J.M.; CASTELLAR, R. Determination of antioxidant constituents in cactus pear fruits. Plant Foods for Human Nutrition, Dordrecth, v. 65, n. 3, p. 253-259, 2010.
FIRUZI, O.; LACANNA, A.; PETRUCCI, R.; MARROSU, G.; SASO, L. Evaluation of the antioxidant activity of flavonoids by "ferric reducing antioxidant power" assay and cyclic voltammetry. Biochimica et Biophysica Acta, Amsterdam, v. 1721, n. 1-3, p. 174-184, 2005.

HOSSAIN, M. A.; RAHMAN, S.M.M. Total phenolics, flavonoids and antioxidant activity of tropical fruit pineapple. Food Research International, Ganesville, v. 44, n. 3, p. 672-676, 2011.

LARRAURI, J.A.; RUPÉREZ, P.; SAURACALIXTO, F. Effect of drying temperature on the stabilitity of polyphenols and antioxidant activity of red grape pomace peels. Journal of Agricultural and Food Chemistry, Washington, v. 45, n. 4, p. 1390-1393, 1997.

LEONG, L.P.; SHUI, G. An investigation of antioxidant capacity of fruit in Singapore markets. Food Chemistry, Washington, v. 76, n. 1, p. 69-75, 2002.

LIMA, A.; SILVA, A. M. O.; TRINDADE, R. A.; TORRES, R, P.; FILHO, J. M. Composição química e compostos bioativos presentes na polpa e na amêndoa do pequi (Caryocar brasiliense, Camb.). Revista Brasileira de Fruticultura, Jaboticabal, v. 29, n. 3, p. 695-698, 2007.

MOKBEL, M. S.; HASHINAGA, F. Evaluation of the antioxidant activity of extracts from buntan (Citrus grandis Osbeck) fruit tissues. Food Chemistry, London, v. 94, n. 4, p. 529-534, 2006.

MOURE, A.; CRUZ, J. M.; FRANCO, D. F.; DOMÍNGUEZ, J. M.; SINEIRO, J.; DOMÍNGUEZ, H.; NÚNEZ, M. J.; CARLOS PARAJÓ, J. C. Natural antioxidants from residual sources, Food Chemistry, Barking, v. 72, n. 1, p. 145-171, 2001.

NEVES, L. C., Frutos- O remédio do futuro. Revista Brasileira de Fruticultura, Jaboticabal, v. 34, n.4 p. i. , 2012. 
PRIOR, R. L.; WU, X. L.; SCHAICH, K. Standardized methods for the determination of antioxidant capacity and phenolics in foods and dietary supplements. Journal of Agricultural and Food Chemistry, Washington, v. 53, n.10, p. 4290-4302, 2005.

ROESLER, R.; MALTA, L.G.; CARRASCO, L.C.; HOLANDA, R.B.; SOUSA, C.A.S.S.; PASTORE,G.M. Atividade antioxidante de frutas do cerrado. Ciência e Tecnologia de Alimentos, Campinas, v2, n.1, p. 53-60, 2007.

RUFINO, M. S. M.; ALVES, R. E.; BRITO, E. S.; JIMÉNEZ. J. P.; CALIXTO. F. S. Bioactive compounds and antioxidant capacities of 18 non-traditional tropical fruits from Brazil. Food Chemistry, London, v. 121, n. 4, p. 996-1002, 2010.

SÁNCHEZ-MORENO, C.; LARRAURI, J. A. Principales métodos para la determinación de la oxidación lipídica. Food Science and Technology International, Washington, v. 4, n. 6, p. 391-399, 1998.
SIVAPRIYA, M.; LEELA, S. Isolation and purification of a novel antioxidant protein from the water extract of Sundakai (Solanum torvum) seeds. Food Chemistry, London, v. 104, n.2, p. 510-517, 2007.

VALKO, M.; LEIBFRITZ, D.; MONCOL, J.; CRONIN, M.T.; MAZUR, M.; TELSER, J. Free radicals and antioxidants in normal physiological functions and human disease. International Journal of Biochemistry and Cell Biology, Oxford, v. 39, n. 1, p. $44-84,2007$

VELIOGLU, Y. S.; MAZZA, G.; GAO, L.; OOMAH, B.D. Antioxidant capacity and total phenolics in selected fruits, vegetables and grain products. Journal of Agricultural and Food Chemistry, Washington, v. 46, n.10, p. 4113-4117, 1998. 